\title{
藏南羊卓雍错流域水化学主离子特征及其控制因素”
}

\author{
孙 瑞 $^{1}$, 张雪芹 ${ }^{1}$, 吴艳红 ${ }^{2}$ \\ (1: 中国科学院地理科学与资源研究所, 北京 100101) \\ (2: 中国科学院对地观测与数字地球科学中心, 北京 100094 )
}

摘 要: 水化学主离子特征是流域湖泊的一个重要特征, 对气候以及河流所经地区的环境具有指示作用. 本文对藏南羊 卓雍错流域水化学主离子组成特征及其控制因素进行分析, 结果显示流域内不同水体 (湖水、河水、地下水)之间的主离 子组成以及水化学类型差异显著. 其中, 羊卓雍错的水化学类型为 $\mathrm{SO}_{4}^{2-}-\mathrm{HCO}_{3}^{-}-\mathrm{Mg}^{2+}-\mathrm{Na}^{+}$, 巴纠错为 $\mathrm{SO}_{4}^{2-}-\mathrm{Mg}^{2+}$ $-\mathrm{Na}^{+}$, 沉错为 $\mathrm{SO}_{4}^{2-}-\mathrm{Na}^{+}-\mathrm{Mg}^{2+}-\mathrm{Ca}^{2+}$, 普莫雍错为 $\mathrm{HCO}_{3}^{-}-\mathrm{SO}_{4}^{2-}-\mathrm{Mg}^{2+}-\mathrm{Ca}^{2+}$, 空姆错为 $\mathrm{HCO}_{3}^{-}-\mathrm{SO}_{4}^{2-}-\mathrm{Ca}^{2+}$; 流域河水中主要阴离子为 $\mathrm{HCO}_{3}^{-}$和 $\mathrm{SO}_{4}^{2-}, \mathrm{Ca}^{2+}$ 为绝对优势阳离子; 流域地下水化学类型则为 $\mathrm{HCO}_{3}^{-}-\mathrm{Ca}^{2+}$. 究其原因, 流域水体化学组成主要受岩石风化作用控制; 除此, 羊卓雍错、巴纠错和沉错水化学组成亦受自身蒸发一结晶作用的影 响. 就人湖河水而言, 羊卓雍错人湖河水整体受碳酸盐岩石风化的影响较大, 蒸发岩溶解的影响次之; 沉错和空姆错人湖 河流 (卡鲁雄曲) 的蒸发岩来源则略大于碳酸盐岩来源; 而硅酸盐对流域内河水的水化学性质影响较小. 与人湖河水相 比, 羊卓雍错和沉错湖水的 $\mathrm{Mg}^{2+} 、 \mathrm{Na}^{+}$和 $\mathrm{SO}_{4}^{2-}$ 含量较高, 而 $\mathrm{Ca}^{2+}$ 和 $\mathrm{HCO}_{3}^{-}$含量较低. 这应该与湖水蒸发强烈使得湖水中 $\mathrm{Ca}^{2+}$ 和 $\mathrm{HCO}_{3}^{-}$析出并沉积到湖底有关. 而空姆错由于湖泊面积小、人湖河水流量大, 致使其湖水与人湖河水的主离子组 成差异不显著.

关键词: 主离子组成;水化学类型;岩石风化;蒸发一结晶; 羊卓雍错流域

\section{Major ion chemistry of water and its controlling factors in the Yamzhog Yumco Basin, South Tibet}

\author{
SUN Rui ${ }^{1}$, ZHANG Xueqin ${ }^{1} \&$ WU Yanhong ${ }^{2}$ \\ (1: Institute of Geographic Sciences and Natural Resources Research, Chinese Academy of Sciences, Beijing 100101, P. R. \\ China)
}

(2: Center for Earth Observation and Digital Earth, Chinese Academy of Sciences, Beijing 100094, P. R. China)

\begin{abstract}
Water chemical composition of a lake and its inflow rivers is an important lake characteristic, which can reflect the climatic and environmental background of the basin where the lake is located and the river flows through. Water samples were collected and their major ions were measured from the major lakes (i. e., Yamzhog Yumco, Bajiu Co, Chen Co, Kongmu Co and Pumoyong Co), inflow rivers, and wells in the Yamzhog Yumco Basin. Possible controlling factors on the major ion compositions from different waterbody were analyzed. Results revealed that the major ion compositions (e. g. hydrochemical types) of the water in the basin were significantly different as follows. The major ion compositions of lake water in Yamzhog Yumco, Bajiu Co, Chen Co, Pumoyong Co and Kongmu Co were $\mathrm{SO}_{4}^{2-}-\mathrm{HCO}_{3}^{-}-\mathrm{Mg}^{2+}-\mathrm{Na}^{+}, \mathrm{SO}_{4}^{2-}-\mathrm{Mg}^{2+}-\mathrm{Na}^{+}, \mathrm{SO}_{4}^{2-}-\mathrm{Na}^{+}-\mathrm{Mg}^{2+}-\mathrm{Ca}^{2+}, \mathrm{HCO}_{3}^{-}-$ $\mathrm{SO}_{4}^{2-}-\mathrm{Mg}^{2+}-\mathrm{Ca}^{2+}$, and $\mathrm{HCO}_{3}^{-}-\mathrm{SO}_{4}^{2-}-\mathrm{Ca}^{2+}$, respectively. For the inflow river water, the major anions were $\mathrm{HCO}_{3}^{-}$and $\mathrm{SO}_{4}^{2-}$ and the preponderant cation was $\mathrm{Ca}^{2+}$. Comparing with the water chemical compositions of inflow rivers, the contents of $\mathrm{Mg}^{2+}, \mathrm{Na}^{+}$and $\mathrm{SO}_{4}^{2-}$ in Yamzhog Yumco and Chen Co were much higher with a relative low contents of $\mathrm{Ca}^{2+}$ and $\mathrm{HCO}_{3}^{-}$. On the contrary, there was little difference for the Kongmu Co and its inflow rivers. In addition, the major ion compositions of well waters were characterized by $\mathrm{HCO}_{3}^{-}-\mathrm{Ca}^{2+}$. Further analysis indicated that the water chemical compositions were mainly controlled by rock weathering in the whole basin, and also by evaporation and crystallization for Yamzhog Yumco, Bajiu Co and Chen Co. For the inflow river waters in the basin, the main controlling factors of chemical compositions were carbonate weathering and evaporite weathering, while the effect of the silicate weathering on the river water chemistry was minor. Thereinto, the dominant controlling processes were carbonate weathering for inflow river waters flowing into Yamzhog Yumco, and the evaporite weathering for the inflow river waters flowing into Chen Co and Kongmu Co. As for the different water chemical characteristics between the inflow river
\end{abstract}

* 国家自然科学基金项目 (40871044,41171062,40901102)资助. 2011-08-26 收稿;2011-11-18 收修改稿. 孙瑞, 女, 1985 年生, 博士研究生; E-mail :feifeiry@ tom. com. 
water and lake water of Yamzhog Yumco and Chen Co, the possible reason should own to the strong evaporation of two lakes which may intensify calcium phosphate precipitation. The small lake area of Kongmu Co and the vast amounts of inflowing river water can explain the little difference of water chemical compositions between the lake and its inflow rivers. The study also showed that the controlling processes of water chemical compositions among inflow rivers were different because the different rock-stratigraphic area they flowed was dominated by physical weathering/erosion. With global warming, the style and intensity of rock weathering would be changed. So it is indispensable to further investigate the speed of rock weathering in the basin and its possible response to climate change.

Keywords: Major ion compositions; hydrochemical types; rock weathering; evaporation and crystallization; Yamzhog Yumco Basin

湖泊与河流水体的化学成分对气候以及河流所经地区的环境具有指示作用. 国内外不少学者对全球主 要水体中的主离子含量与流域的气候条件和区域地质岩性的关系进行了研究 ${ }^{[1-10]}$. Gibbs 基于对全球大量雨 水、河水、湖水和海洋水的分析, 认为大气降水输人、岩石风化和蒸发一结晶过程是全球地表水化学组成的三 大控制因素 ${ }^{[1]}$. 在我国, 长江、黄河、雅鲁藏布江、澜沧江及鸭绿江等的河水离子组成主要受碳酸盐岩和蒸发 岩风化作用的影响, 受铝硅酸盐岩溶解的影响较小 ${ }^{[8]}$; 青海湖流域水体化学组成受岩石风化以及蒸发-结晶 作用的影响, 其河水化学组成主要受碳酸盐岩溶解控制 ${ }^{[9]}$; 西藏纳木错湖水主要受蒸发一结晶作用影响, 而 河水则主要受岩石风化作用影响 ${ }^{[10]}$.

青藏高原被称为地球的 “第三极”, 对气候变化非常敏感 ${ }^{[11]}$, 且人类活动相对较弱. 自 2004 年以来, 位 于青藏高原南部的羊卓雍错流域的湖泊 (包括羊卓雍错、巴纠错、沉错、空姆错和普莫雍错) 整体萎缩剧烈, 这引起了西藏自治区政府及社会各界的普遍关注. 目前, 在该流域开展了流域年均气温和降水量 ${ }^{[12]}$ 、主要湖 泊水质状况 ${ }^{[13-15]}$ 、羊卓雍错湖泊水位和面积变化 ${ }^{[16]}$ 、普莫雍错湖底地形测量与湖水及其周围入湖河流水体

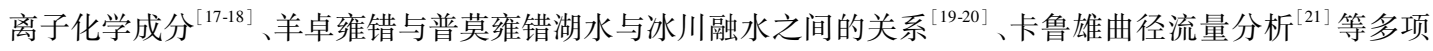
研究. 整体看, 流域内不同水体之间的水化学离子组成及其对比分析匮乏, 流域内多数湖泊 (普莫雍错除外) 及其人湖河水与地下水化学离子特征研究亟待尽快展开. 因此, 本研究分析了藏南羊卓雍错流域内不同水 体 (湖水、河水、地下水) 的主要离子组成特征 (水化学特征、水化学类型) 及其控制因素, 为了解该流域湖泊 特征提供基础资料.

\section{1 区域概况}

羊卓雍错流域 (包括羊卓雍错、巴纠错、沉错、普莫雍错和空姆错) 是藏南内陆湖泊最为集中的区域 ${ }^{[15]}$. 流域四周高山环绕, 北距雅鲁藏布江 $8.0 \sim 10.0 \mathrm{~km}$, 其间以甘巴拉山相隔; 西面为年楚河流域, 以宁金抗沙 雪山为分水岭; 南面为喜马拉雅山脉, 有蒙达岗日诸雪山. 流域面积 $9048.0 \mathrm{~km}^{2}$, 各湖水面积总和为 $985.1 \mathrm{~km}^{2}$ (2). 其中, 羊卓雍错是该流域内面积最大的湖泊 (面积为 $588.9 \mathrm{~km}^{2}$ ) ; 其岸线曲折, 多湖汊、岬湾, 湖 面海拔为 $4445.7 \mathrm{~m}^{3}$; 多年平均水位为 $4439.1 \mathrm{~m}^{4}$. 主要补给河流自东向西有嘎马林河、卡洞加曲、曲清河、 香达曲、浦宗曲、牙间曲、卡鲁雄曲等( 图 1 ). 除小部分水量流人沉错外, 卡鲁雄曲绝大部分水量流人空姆错, 并在夏季补给羊卓雍错; 普莫雍错东南部有一条经人工改造的出湖河流, 高湖面时湖水沿此河流经卡洞加 曲注人羊卓雍错; 沉错、巴纠错与羊卓雍错并无直接水源联系. 流域属藏南山地灌丛草原半干旱气候, 年均 温度为 $2.8^{\circ} \mathrm{C}$; 多年平均降水为 $363.4 \mathrm{~mm}$, 全年总降水量的 $95 \%$ 左右集中于每年的 5-9 月; 多年平均水面 蒸发量为 $1296.7 \mathrm{~mm}^{(5)}$.

(1) 流域面积基于分辨率为 $90 \mathrm{~m}$ 的 SRTM DEM 数据,应用 ArcGIS 提取获得.

(2) 湖泊面积根据 1972-2009 年间 37 幅遥感影像数据提取,并进行平均计算.

(3) 湖泊海拔根据 2009 年 7 月利用 GPS 野外实测的湖泊采样点海拔平均计算.

(4) 湖泊水位根据白地水文站 1974-2009 年多年平均水位计算.

(5) 气温 (降水) 和水面蒸发分别根据浪卡子气象站 1961-2010 年、白地水文站 1977-1995 年 $20 \mathrm{~m}^{2}$ 蒸发池多年平 均计算. 


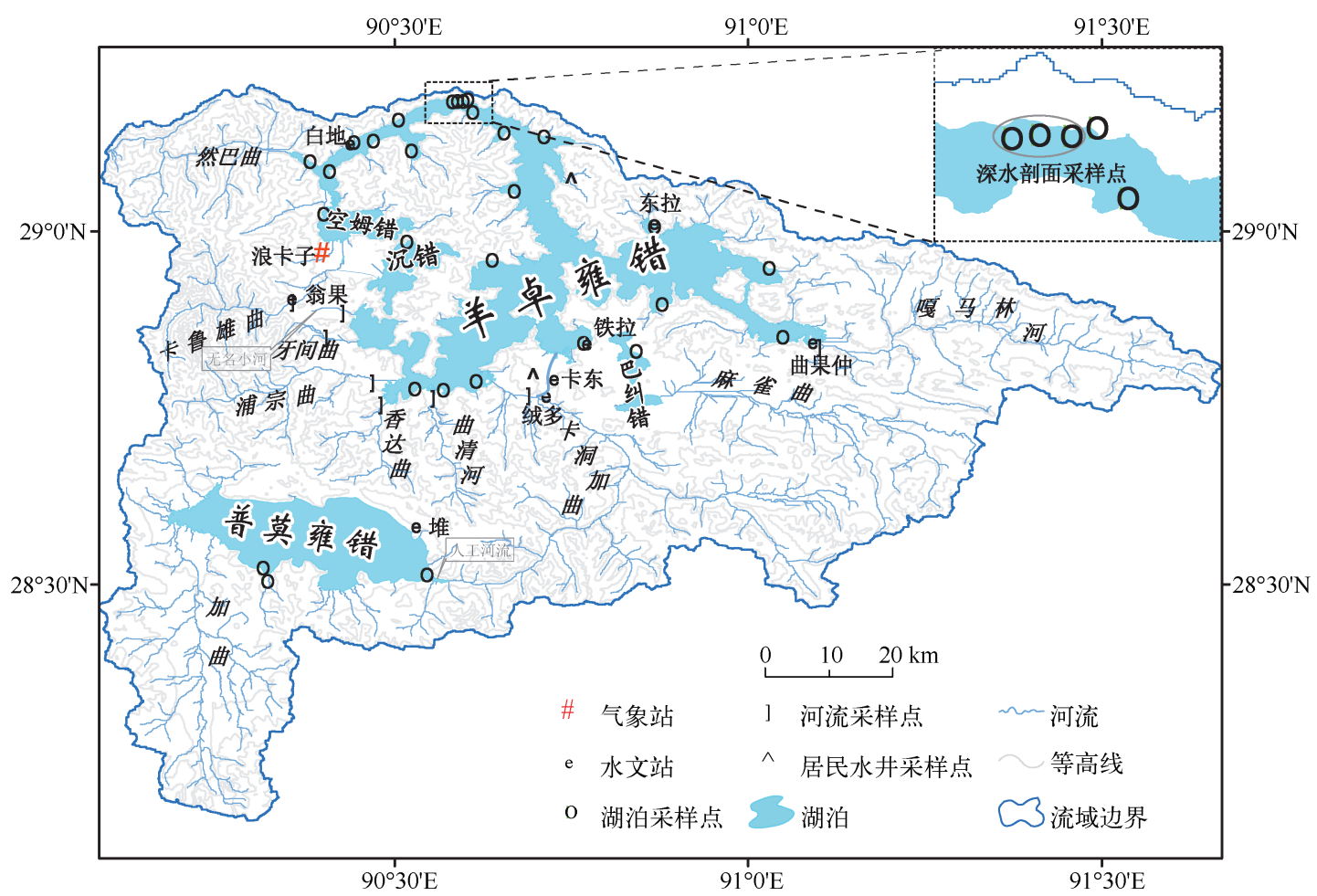

图 1 羊卓雍错流域及其采样点 (本图流域边界及水系根据 2000 年 2 月 11 日至 22 日美国航天 飞机于飞行中用雷达测图技术得到的分辨率为 $90 \mathrm{~m}$ 的 SRTM DEM 数据提取, 并参考了我国 1974 年制图出版的 1: 100000 国家基本地形图)

Fig. 1 Drainage system of Yamzhog Yumco Basin and the sampling sites (The drainage system and boundary of the basin were based on the SRTM DEM data with the resolution of $90 \mathrm{~m}$, and rectified by

the National Basic Topographic map, an image of China published in 1974 with the scale of 1:100000)

在地层分区上, 本区位于喜马拉雅区-拉轨岗日分区. 其中, 流域西部、西南部以及南面部分地区分布三 叠系涅如群 $\left(\mathrm{T}_{3} \mathrm{ny}\right)$. 上部为钙质砂岩、细砂岩、长石石英砂岩和深灰色板岩, 常夹硅质岩、灰岩, 板岩含菱铁 质和砂质结核及黄铁矿细粒; 下部以深灰色页岩为主, 含砂质结核. 流域西南以及南面部分地区分布侏罗系 日当组 $\left(J_{1} r\right)$ 和遮拉组 $\left(J_{2}\right)$. 日当组岩性以黑色页岩为主, 含硅质结核, 并有辉绿玢岩侵位于页岩中; 遮拉组 岩性为一套含中、基性火山岩的深海一浅海菊石细碎屑岩. 流域东南部地区分布白严系加不拉组 $\left(\left(J_{3}-K_{1}\right) j\right)$, 剖面主要是灰黑色页岩、黑色含细粉砂的钙一硅质页岩、硅质泥岩, 夹燧石层及许多灰岩结核 或透镜体, 少数为砂岩透镜体、碧玉岩透镜体, 并具有各种样式的滑塌堆积, 组成比较复杂的复理石浊流沉 积; 且下部含有安山岩、火山角砾岩、凝灰质砂岩, 并出现砂岩、砂砾岩、砾状硅质灰岩等 ${ }^{[22]}$.

\section{2 采样与测定方法}

2010 年 7 月在藏南羊卓雍错流域内 5 个主要湖泊、8 条河流以及附近居民水井处共设 48 个采样点 ( 图 1). 其中, 在羊卓雍错设 32 个采样点 (湖周边表层采样点 20 个, 湖中心 3 个采样点垂直采样 4 层共计 12 个); 普莫雍错设 3 个采样点, 巴纠错、沉错、空姆错及 8 条河流处各设 1 个采样点, 均只取表层水样; 在附近 2 口居民饮用水井处各设 1 个采样点.

测定参数包括 $\mathrm{pH}$ 值、电导率、溶解性总固体 ( TDS ) 、八大离子 $\left(\mathrm{K}^{+} 、 \mathrm{Na}^{+} 、 \mathrm{Ca}^{2+} 、 \mathrm{Mg}^{2+} 、 \mathrm{CO}_{3}^{2-} 、 \mathrm{HCO}_{3}^{-} 、 \mathrm{Cl}^{-}\right.$、 $\left.\mathrm{SO}_{4}^{2-}\right)$ 、二氧化硅 $\left(\mathrm{SiO}_{2}\right)$ 等. 其中, $\mathrm{pH}$ 值、电导率、TDS 等利用多参数水质测定仪 ( $\left.\mathrm{HI} 9828\right)$ 现场测定. 其它参 
数的测定均在中国科学院地理科学与资源研究所的实验室完成. 测定的仪器 (方法) 如下: $\mathrm{K}^{+} 、 \mathrm{Na}^{+} 、 \mathrm{Ca}^{2+} 、$ $\mathrm{Mg}^{2+} 、 \mathrm{SiO}_{2}$ 采用电感耦合等离子体发射光谱仪 ( ICP-OES) 测定, $\mathrm{CO}_{3}^{2-} 、 \mathrm{HCO}_{3}^{-}$采用双指示剂中和法测定, $\mathrm{Cl}^{-}$、 $\mathrm{SO}_{4}^{2-}$ 采用离子色谱仪 ( LC-10ADvp) 测定.

\section{3 结果与分析}

\section{1 羊卓雍错流域水化学特征与水化学类型}

2010 年 7 月羊卓雍错流域河水整体呈弱碱性, $\mathrm{pH}$ 值变化范围为 $8.1 \sim 9.0$; 电导率变化范围为 $164.0 \sim$ $713.0 \mu \mathrm{S} / \mathrm{cm}$; TDS 含量变化范围为 $101.0 \sim 382.0 \mathrm{mg} / \mathrm{L}$, 平均为 $210.4 \mathrm{mg} / \mathrm{L}$, 高于世界河流 TDS 平均值 $(115 \mathrm{mg} / \mathrm{L})^{[23]}$. 总硬度变化范围为 $99.5 \sim 307.7 \mathrm{mg} / \mathrm{L}$, 平均为 $190.5 \mathrm{mg} / \mathrm{L}$, 大多属于硬水和极硬水 ${ }^{(1)}$. 不同 河流的水化学类型(2)差异较大: 嘎马林河为 $\mathrm{HCO}_{3}^{-}-\mathrm{Ca}^{2+}-\mathrm{Na}^{+}$、香达曲为 $\mathrm{HCO}_{3}^{-}-\mathrm{Ca}^{2+}$ 、牙间曲及无名小河 为 $\mathrm{HCO}_{3}^{-}-\mathrm{SO}_{4}^{2-}-\mathrm{Ca}^{2+}$ 、卡洞加曲为 $\mathrm{SO}_{4}^{2-}-\mathrm{HCO}_{3}^{-}-\mathrm{Ca}^{2+}-\mathrm{Mg}^{2+}$ 、曲清河、浦宗曲和卡鲁雄曲均为 $\mathrm{SO}_{4}^{2-}-$ $\mathrm{HCO}_{3}^{-}-\mathrm{Ca}^{2+}$.

两处地下水样品的水化学类型均为 $\mathrm{HCO}_{3}^{-}-\mathrm{Ca}^{2+}$. TDS 含量分别为 $139.0 、 216.0 \mathrm{mg} / \mathrm{L}$; pH 值分别为7.9 和 8.3 ; 电导率分别为 $263.0 、 332.0 \mu \mathrm{S} / \mathrm{cm}$; 总硬度分别为 $143.3 、 156.9 \mathrm{mg} / \mathrm{L}$, 属于硬水.

流域内湖水整体呈碱性, 各湖泊水化学类型差异显著. 其中, 羊卓雍错的 $\mathrm{pH}$ 值变化范围为 $9.1 \sim 9.5$, 平 均为 9.3 ; 电导率范围为 $1931.0 \sim 2673.0 \mu \mathrm{S} / \mathrm{cm}$, 平均为 $2175.0 \mu \mathrm{S} / \mathrm{cm}$; TDS 含量变化范围为 $1147.0 \sim$ $1438.0 \mathrm{mg} / \mathrm{L}$, 平均为 $1277.6 \mathrm{mg} / \mathrm{L}$, 属稍咸水 ${ }^{3}$; 总硬度变化范围为 $745.0 \sim 825.8 \mathrm{mg} / \mathrm{L}$, 平均为 $793.5 \mathrm{mg} / \mathrm{L}$, 属极硬水, 且高于世界卫生组织建议的用水总硬度 $(500 \mathrm{mg} / \mathrm{L})^{[24]}$; 水化学类型大多为 $\mathrm{SO}_{4}^{2-}-\mathrm{HCO}_{3}^{-}-\mathrm{Mg}^{2+}$ $-\mathrm{Na}^{+}$. 巴纠错的水化学类型为 $\mathrm{SO}_{4}^{2-}-\mathrm{Mg}^{2+}-\mathrm{Na}^{+}$, TDS 为 $1675.0 \mathrm{mg} / \mathrm{L}$, 总硬度为 $1296.2 \mathrm{mg} / \mathrm{L}$, 为硬度极 高的稍咸水. 沉错的水化学类型为 $\mathrm{SO}_{4}^{2-}-\mathrm{Na}^{+}-\mathrm{Mg}^{2+}-\mathrm{Ca}^{2+}$ 型, TDS 含量为 $779.0 \mathrm{mg} / \mathrm{L}$, 总硬度为 $450.1 \mathrm{mg} / \mathrm{L}$; 普莫雍错为 $\mathrm{HCO}_{3}^{-}-\mathrm{SO}_{4}^{2-}-\mathrm{Mg}^{2+}-\mathrm{Ca}^{2+}$, TDS 含量为 $224.0 \mathrm{mg} / \mathrm{L}$, 总硬度为 $218.2 \mathrm{mg} / \mathrm{L}$; 空姆 错为 $\mathrm{HCO}_{3}^{-}-\mathrm{SO}_{4}^{2-}-\mathrm{Ca}^{2+}$ 型, TDS 含量为 $208.0 \mathrm{mg} / \mathrm{L}$, 总硬度为 $228.0 \mathrm{mg} / \mathrm{L}$; 均属于硬度极高的淡水.

\section{2 各种水体主要离子组成}

利用阴离子 $\mathrm{SO}_{4}^{2-}-\mathrm{Cl}^{-}-\left(\mathrm{CO}_{3}^{2-}+\mathrm{HCO}_{3}^{-}\right)$组成的三角图和阳离子 $\mathrm{Ca}^{2+}-\mathrm{Mg}^{2+}-\left(\mathrm{Na}^{+}+\mathrm{K}^{+}\right)$组成的三 角图可以表明不同水体的化学组成特征, 从而辨别其控制端元. 羊卓雍错流域各种水体的主要阴阳离子组 成见图 2.

在阴离子三角图中, 流经碳酸盐岩地区的河流以 $\mathrm{HCO}_{3}^{-}$为主导, 数据点落在 $\mathrm{CO}_{3}^{2-}+\mathrm{HCO}_{3}^{-}$一端; 流经蒸 发岩地区的河流 $\mathrm{SO}_{4}^{2-} 、 \mathrm{Cl}^{-}$含量较高, 其数据点落在 $\mathrm{SO}_{4}^{2-}-\mathrm{Cl}^{-}$线上, 远离 $\mathrm{CO}_{3}^{2-}+\mathrm{HCO}_{3}^{-}$一端. 在阳离子三角 图中, 主要受碳酸盐岩影响的河流, 其数据点会落在 $\mathrm{Ca}^{2+}-\mathrm{Mg}^{2+}$ 线上, 靠近 $\mathrm{Ca}^{2+}$ 端元; 主要受蒸发岩影响的 河流, 其数据点偏向 $\mathrm{Na}^{+}+\mathrm{K}^{+}$端元 ${ }^{[9]}$. 羊卓雍错流域河水的阴离子数据点大多分布在 $\mathrm{SO}_{4}^{2-}-\mathrm{Cl}^{-}$线上, 靠近 $\mathrm{SO}_{4}^{2-}$ 端, $\mathrm{Cl}^{-}$含量甚微且变化较小. 其中, 阴离子的 4 个数据点离 $\mathrm{CO}_{3}^{2-}+\mathrm{HCO}_{3}^{-}$一端较远, 暗示其河水离子组 成主要受蒸发岩溶解的影响; 而其余数据点离 $\left(\mathrm{CO}_{3}^{2-}+\mathrm{HCO}_{3}^{-}\right)$一端较近, 暗示其河水离子组成受碳酸盐岩 的影响较大. 而阳离子的数据点分布在 $\left(\mathrm{Na}^{+}+\mathrm{K}^{+}\right)-\mathrm{Ca}^{2+}$ 线上, 靠近 $\mathrm{Ca}^{2+}$ 端元, $\mathrm{Ca}^{2+}$ 含量远大于 $\mathrm{Mg}^{2+}($ 数 据点分布在 $\mathrm{mn}$ 线以下), 为绝对优势阳离子. 根据 8 条人湖河流的离子当量浓度平均值计算, $\mathrm{HCO}_{3}^{-}$和 $\mathrm{SO}_{4}^{2-}$ 分别占阴离子总量的 $50.4 \% 、 42.7 \% ; \mathrm{Ca}^{2+}$ 占阳离子总量的 $74.0 \%$.

两处地下水样品均以 $\mathrm{CO}_{3}^{2-}+\mathrm{HCO}_{3}^{-}$为绝对优势阴离子(数据点均靠近 $\mathrm{CO}_{3}^{2-}+\mathrm{HCO}_{3}^{-}$的高值端和 $\mathrm{SO}_{4}^{2-}$ 低值端, 并远离 $\mathrm{Cl}^{-}$端), 分别占阴离子总量的 $90.7 \%$ 和 $82.3 \%, \mathrm{SO}_{4}^{2-}$ 和 $\mathrm{Cl}^{-}$含量甚微. 以 $\mathrm{Ca}^{2+}$ 为绝对优势阳

(1) 总硬度 $\left(\mathrm{mg} \mathrm{CaCO}_{3} / \mathrm{L}\right)=2.497 \times \mathrm{Ca}($ 以 $\mathrm{mg} \mathrm{Ca} / \mathrm{L})+4.118 \times \mathrm{Mg}$ (以 $\left.\mathrm{mg} \mathrm{Mg} / \mathrm{L}\right)$. 根据总硬度可将水体分为软水 $(<50 \mathrm{mg}$ $\left.\mathrm{CaCO}_{3} / \mathrm{L}\right)$ 、中等水 $\left(51 \sim 120 \mathrm{mg} \mathrm{CaCO}_{3} / \mathrm{L}\right)$ 、硬水 $(121 \sim 180 \mathrm{mg} \mathrm{CaCO} / \mathrm{L})$ 和极硬水 $\left(>180 \mathrm{mg} \mathrm{CaCO}_{3} / \mathrm{L}\right)^{[24]}$.

(2) 阴阳离子均以当量浓度含量大于 $25 \%$ 的离子计 ${ }^{[9,23]}$.

(3) 按 TDS 大小可将水体划分为淡水 $(<1000 \mathrm{mg} / \mathrm{L})$ 、稍咸水 $(1000 \sim 3000 \mathrm{mg} / \mathrm{L})$ 、中度咸水 $(3000 \sim 10000 \mathrm{mg} / \mathrm{L})$ 、 极咸水 $(10000 \sim 35000 \mathrm{mg} / \mathrm{L})$ 和盐卤水 $(>35000 \mathrm{mg} / \mathrm{L})^{[24]}$. 
离子 (数据点分布在 $\mathrm{mn}$ 线以下, 更靠近 $\mathrm{Ca}^{2+}$ 端), 分别占阳离子总量的 $83.9 \%$ 和 $61.3 \%, \mathrm{Mg}^{2+}$ 和 $\mathrm{K}^{+}+\mathrm{Na}^{+}$ 含量均较低.

羊卓雍错湖水的阴离子和阳离子数据点分别较集中地靠近 $\mathrm{SO}_{4}^{2-}$ 端和 $\mathrm{Mg}^{2+}$ 端, 说明湖水 $\mathrm{Cl}^{-}$与 $\mathrm{Ca}^{2+}$ 含 量普遍较小, 且变化不大. 湖水主要阴离子和阳离子分别为 $\mathrm{SO}_{4}^{2-}$ 和 $\mathrm{Mg}^{2+}$. 其中, $\mathrm{SO}_{4}^{2-}$ 占阴离子总量的 $50.4 \% ; \mathrm{CO}_{3}^{2-}$ 和 $\mathrm{HCO}_{3}^{-}$分别占阴离子总量的 $15.3 \%$ 和 $26.3 \%$, 这是由于羊卓雍错湖水 $\mathrm{pH}>9.0$, 大气 $\mathrm{CO}_{2}$ 溶 人水中电离生成 $\mathrm{CO}_{3}^{2-[24]}$, 导致其浓度相对较大; $\mathrm{Mg}^{2+}$ 占阳离子总量的 $54.5 \% ; \mathrm{Na}^{+}+\mathrm{K}^{+}$占阳离子总量的 $44.3 \%$. 羊卓雍错湖水的 $\mathrm{SO}_{4}^{2-} 、 \mathrm{Mg}^{2+}$ 和 $\mathrm{Na}^{+}$总量远高于人湖河水, 而 $\mathrm{HCO}_{3}^{-}$和 $\mathrm{Ca}^{2+}$ 总量低于人湖河水. 这一 特征在普莫雍错 ${ }^{[18]}$ 、纳木错 ${ }^{[25]}$ 等青藏高原湖泊 ${ }^{[26]}$ 中亦有所发现. 究其原因, 羊卓雍错为封闭型湖泊, 湖水 长期强烈蒸发使得湖水中的 $\mathrm{Ca}^{2+}$ 和 $\mathrm{HCO}_{3}^{-}$析出并沉积到湖底, 从而造成 $\mathrm{Mg}^{2+} 、 \mathrm{Na}^{+}$和 $\mathrm{SO}_{4}^{2-}$ 比例相对升高.

巴纠错、沉错、普莫雍错和空姆错湖水的阴离子数据点均靠近 $\mathrm{SO}_{4}^{2-}$ 端, 说明各湖泊水体中 $\mathrm{Cl}^{-}$含量甚 微. 其中,巴纠错和沉错的阴离子均以 $\mathrm{SO}_{4}^{2-}$ 为主, 分别占阴离子总量的 $80.9 \%$ 和 $81.8 \%$; 普莫雍错和空姆错 均以 $\mathrm{CO}_{3}^{2-}+\mathrm{HCO}_{3}^{-}$为主, 分别占阴离子总量的 $73.3 \%$ 和 $55.6 \%$. 巴纠错和普莫雍错湖水的阳离子数据点均 分布在 $\mathrm{mn}$ 线以上, 主要阳离子为 $\mathrm{Mg}^{2+}$, 均占阳离子总量的 $55.6 \%$; 巴纠错湖水 $\mathrm{K}^{+}+\mathrm{Na}^{+}$含量亦较大, 占阳 离子总量的 $35.0 \%$; 普莫雍错湖水中 $\mathrm{Ca}^{2+}$ 占阳离子总量的 $25.3 \%$, 为次主要阳离子. 沉错湖水主要阳离子 为 $\mathrm{K}^{+}+\mathrm{Na}^{+}$, 占阳离子总量的 $42.2 \%, \mathrm{Ca}^{2+}$ 与 $\mathrm{Mg}^{2+}$ 含量相当 (数据点几乎落在 $\mathrm{mn}$ 线上). 空姆错湖水 $\mathrm{Ca}^{2+}$ 为绝对优势阳离子 (数据点分布在 $\mathrm{mn}$ 线以下并靠近 $\mathrm{Ca}^{2+}$ 端), 占总量的 $74.8 \%$, 其主要阴离子含量与人湖 河水略有差异, 而绝对优势阳离子与人湖河水 (卡鲁雄曲) 相同, 这主要是由于空姆错湖泊面积小、人湖河水 流量大,湖水化学性质对入湖河水反应敏感.

\section{3 Gibbs 图}

Gibbs 图可直观地比较地表水的化学组成、形成原因 (即大气降水、岩石风化、蒸发一结晶) 以及彼此间的 相互关系 ${ }^{[1]}$. 其纵坐标以对数表示 TDS, 横坐标以算术值表示质量浓度比, 即阳离子 $\mathrm{Na}^{+} /\left(\mathrm{Na}^{+}+\mathrm{Ca}^{2+}\right)$ 或 阴离子 $\mathrm{Cl}^{-} /\left(\mathrm{Cl}^{-}+\mathrm{HCO}_{3}^{-}\right)$的比值. 全球河流、湖泊及主要海洋水体的离子组分值几乎全部落在图 3 中的虚 线内. 但是, Gibbs 图主要基于大型湖泊和河流,对一些小型水体以及干旱/半干旱地区小型湖泊不一定适 用. 因此,对不同区域水化学及其控制因素的调查仍有必要.

羊卓雍错湖水及 2 个河水数据点落在 TDS- $\mathrm{Na}^{+} /\left(\mathrm{Na}^{+}+\mathrm{Ca}^{2+}\right)$ 图和 $\mathrm{TDS}-\mathrm{Cl}^{-} /\left(\mathrm{Cl}^{-}+\mathrm{HCO}_{3}^{-}\right)$图的虚 框外; 巴纠错与沉错的数据点落在 TDS- $\mathrm{Na}^{+} /\left(\mathrm{Na}^{+}+\mathrm{Ca}^{2+}\right)$ 图的虚框内, 但落在 TDS- $\mathrm{Cl}^{-} /\left(\mathrm{Cl}^{-}+\mathrm{HCO}_{3}^{-}\right)$ 图的虚框外; 其余数据点则均分布于虚框内, 且都落在岩石风化控制区 (图 3). 考虑到 2 个河水数据点极靠近 虚框,其水化学组成来源可看作与其它河水相似,即主要受岩石风化作用控制; 地下水、普莫雍错和空姆错湖 水化学组成亦主要受岩石风化作用控制; 而羊卓雍错、巴纠错和沉错湖水化学组成的控制因素需进一步探讨.

河水物质组成是湖水物质来源的最重要途径. 羊卓雍错、巴纠错和沉错湖水化学组成与河水差异较大: 羊 卓雍错、巴纠错和沉错湖水数据点均位于纵坐标 TDS 的高值区, 而河水的数据点则位于低值区; 由于高 $\mathrm{Ca}^{2+}$ 和 $\mathrm{HCO}_{3}^{-}$含量, 多数河水数据点位于 TDS- $\mathrm{Na}^{+} /\left(\mathrm{Na}^{+}+\mathrm{Ca}^{2+}\right)$ 图和 $\mathrm{TDS}-\mathrm{Cl}^{-} /\left(\mathrm{Cl}^{-}+\mathrm{HCO}_{3}^{-}\right)$图横坐标的低值 区; TDS- $\mathrm{Na}^{+} /\left(\mathrm{Na}^{+}+\mathrm{Ca}^{2+}\right)$ 图和 TDS- $\mathrm{Cl}^{-} /\left(\mathrm{Cl}^{-}+\mathrm{HCO}_{3}^{-}\right)$图显示羊卓雍错湖水数据点均落在河水数据点的 右侧; 巴纠错和沉错数据点的 $\mathrm{Na}^{+} /\left(\mathrm{Na}^{+}+\mathrm{Ca}^{2+}\right)$ 比值位于羊卓雍错与河水之间, $\mathrm{Cl}^{-} /\left(\mathrm{Cl}^{-}+\mathrm{HCO}_{3}^{-}\right)$比值与 羊卓雍错相近. 差异原因如前所述, 即由湖水强烈蒸发所致 ( 自 2003 年以来湖泊面积萎缩剧烈 (1). 这同时说明 影响羊卓雍错、巴纠错和沉错湖水化学性质的主要过程为人湖河水化学离子的输人和自身蒸发一结晶作用.

综上所述, 羊卓雍错、巴纠错和沉错湖水化学组成主要受人湖河水化学离子的输人和自身蒸发一结晶作 用的影响; 空姆错和普莫雍错湖水、流域内河水和地下水化学组成则主要受岩石风化作用控制. 因此,本文 将进一步分析河水中主要离子的来源.

\section{4 河水中主要离子来源}

陆地水溶解盐的可能来源包括大气携带的海盐(循环盐)成分、可溶性岩石 (蒸发岩、硅酸盐、碳酸盐和

(1) 田 园,张雪芹,孙 瑞. 基于多源、多时相遥感影像的高原湖泊提取方法与不确定性分析. 冰川冻土,2012 (待刊). 

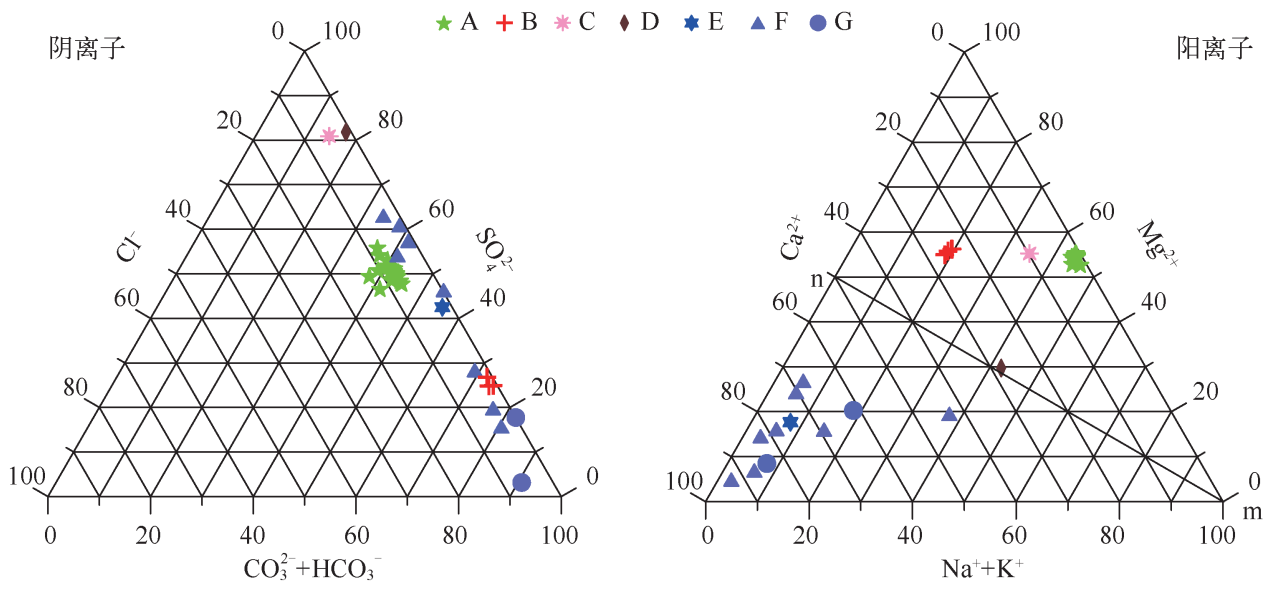

图 2 羊卓雍错流域水体的主要离子当量浓度组成三角图

$\left(m n\right.$ 线: $\mathrm{Ca}^{2+} / \mathrm{Mg}^{2+}=1 ; A 、 B 、 C 、 D 、 E 、 F 、 G$ 分别表示羊卓雍错湖水、普莫雍错湖水、 巴纠错湖水;沉错湖水、空姆错湖水、河水、地下水，下同）

Fig. 2 Ternary plots showing the relative abundances (in equivalent units) (Line $\mathrm{mn}$ : $\mathrm{Ca}^{2+} / \mathrm{Mg}^{2+}=1$;

In legend, A, B, C, D, E, F and G show the lake water of Yamzhog Yumco,

Pumoyong Co, Bajiu Co, Chen Co, Kongmu Co, the river water and the well water, respectively)
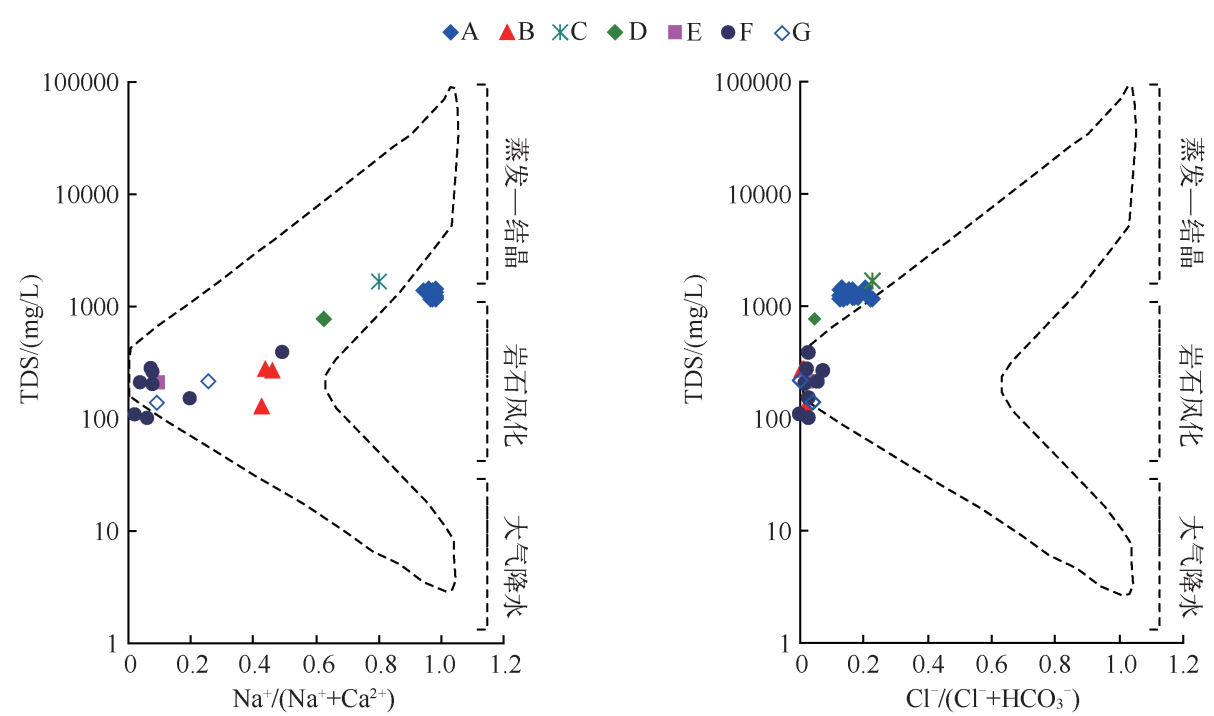

图 3 羊卓雍错流域水离子在 Gibbs 图上的分布

Fig. 3 Plots of the major ions within the Gibbs boomerang envelope for waters in the Yamzhog Yumco Basin 硫化物) 的风化物和人类活动产生的污染物 ${ }^{[27]}$. 研究区人烟稀少, 降水对本区地表水离子影响亦不大 ${ }^{[21]}$. 据 此, 可溶性岩石的风化物是研究区水化学离子的主要可能来源, 这与 Gibbs 图中河水数据点均落在岩石风化 控制区, 并远离大气降水控制区相一致. 在天然条件下, 水体 $\mathrm{HCO}_{3}^{-}$主要来源于碳酸盐的溶解; $\mathrm{SO}_{4}^{2-} 、 \mathrm{Cl}^{-}$主 要来源于蒸发岩的溶解; $\mathrm{Ca}^{2+} 、 \mathrm{Mg}^{2+}$ 主要来源于碳酸盐、蒸发岩和硅酸盐; $\mathrm{Na}^{+} 、 \mathrm{~K}^{+}$则主要来源于蒸发岩和硅 酸盐的风化产物 ${ }^{[28]}$. 
河水 $\left(\mathrm{Ca}^{2+}+\mathrm{Mg}^{2+}\right) /\left(\mathrm{Na}^{+}+\mathrm{K}^{+}\right)$比值可以作为判别流域不同岩石风化相对强度的指标. 碳酸盐岩风化 控制的河流 $\left(\mathrm{Ca}^{2+}+\mathrm{Mg}^{2+}\right) /\left(\mathrm{Na}^{+}+\mathrm{K}^{+}\right)$比值较高; 含蒸发岩的流域 $\left(\mathrm{Ca}^{2+}+\mathrm{Mg}^{2+}\right) /\left(\mathrm{Na}^{+}+\mathrm{K}^{+}\right)$比值较 低 ${ }^{[9]}$. 羊卓雍错人湖河水 (含卡鲁雄曲) $\left(\mathrm{Ca}^{2+}+\mathrm{Mg}^{2+}\right) /\left(\mathrm{Na}^{+}+\mathrm{K}^{+}\right)$比值在 $1.7 \sim 35.3$ 之间, 平均值为 16.8 , 与以碳酸盐岩风化为主的普莫雍错人湖河水的比值 $(2 \sim 25)^{[18]}$ 相近; 远高于主要受蒸发岩溶解影响的塔克 拉玛干沙漠周边河流的比值 $(0.89)^{[23]}$, 以及世界河流平均值 $(2.2)^{[23,29]}$. 可见,羊卓雍错人湖河水整体受碳 酸盐岩风化的影响较大. 在不是以碱土金属的硅酸盐为主的地质背景下 ${ }^{[22]}$, 羊卓雍错人湖河水 $\left(\mathrm{Ca}^{2+}+\right.$ $\left.\mathrm{Mg}^{2+}\right) /\left(\mathrm{Na}^{+}+\mathrm{K}^{+}\right)$比值亦与地壳硅酸盐中的比例 1 相差甚大 ${ }^{[30]}$, 且河水中硅含量较低 $\left(\mathrm{SiO}_{2}\right.$ 浓度范围为 $3.1 \sim 10.1 \mathrm{mg} / \mathrm{L})$, 说明硅酸盐对流域内河水化学性质的影响很小.

嘎马林河、香达曲、牙间曲及无名小河的数据点均处于 $\mathrm{SO}_{4}^{2-}+\mathrm{Cl}^{-}$与 $\mathrm{HCO}_{3}^{-}$的 $1: 1$ 等值线上方, 暗示碳 酸盐岩来源大于蒸发岩来源; 而卡洞加曲、曲清河、浦宗曲、卡鲁雄曲的数据点处于等值线下方, 暗示蒸发岩 来源大于碳酸盐岩来源 (图 4a). $\mathrm{Mg}^{2+}+\mathrm{Ca}^{2+}$ 与 $\mathrm{HCO}_{3}^{-}$含量关系图也显示, 嘎马林河、香达曲、牙间曲及无名 小河的数据点靠近 1:1 等值线,说明碳酸盐溶解是控制此 4 条河流水化学离子的主要因素; 其余数据点偏离 1:1 等值线且处于该线下方, 暗示碳酸盐岩的风化作用不能完全解释水中的 $\mathrm{Mg}^{2+}+\mathrm{Ca}^{2+}$ 组成 (图 4b). 大多 数据点靠近 $\mathrm{Mg}^{2+}+\mathrm{Ca}^{2+}$ 与 $\mathrm{HCO}_{3}^{-}+\mathrm{SO}_{4}^{2-}$ 的 $1: 1$ 等值线 (图 4c), 表明蒸发岩的溶解是卡洞加曲、曲清河、浦 宗曲和卡鲁雄曲等人湖河流水体中 $\mathrm{Mg}^{2+} 、 \mathrm{Ca}^{2+}$ 和 $\mathrm{SO}_{4}^{2-}$ 的重要可能来源.

当蒸发岩的溶解对水化学组成起主要作用时, 水中 $\mathrm{K}^{+}+\mathrm{Na}^{+}$与 $\mathrm{Cl}^{-}$的含量比值应为 $1: 1^{[1,23]} \cdot \mathrm{K}^{+}+\mathrm{Na}^{+}$ 与 $\mathrm{Cl}^{-}$的关系图 (图 4d) 所示, 除嘎马林河外,其余各河流的数据点均接近 1:1 等量线,表明蒸发岩中的石 盐 $(\mathrm{NaCl})$ 和钾石盐 $(\mathrm{KCl})$ 是人湖河水 $\mathrm{Na}^{+} 、 \mathrm{~K}^{+}$和 $\mathrm{Cl}^{-}$的主要来源; 而嘎马林河 $\mathrm{K}^{+}+\mathrm{Na}^{+}$与 $\mathrm{Cl}^{-}$的比值为 10.4 , 这说明蒸发岩对嘎马林河主要离子组成的影响非常小, 河水中 $\mathrm{Na}^{+}$与 $\mathrm{K}^{+}$应该主要来源于硅酸盐的 风化.

\section{4 结论与讨论}

本文对藏南羊卓雍错流域水化学主离子组成特征及其控制因素进行了分析. 首先, 基于三角图说明流 域内不同水体之间的主要离子组成差异显著. 继而, Gibbs 图揭示了流域内水体化学成分主要受岩石风化作 用控制, 羊卓雍错、巴纠错和沉错湖水主离子组成亦受自身蒸发一结晶作用影响. 在此基础上, 利用河水主 离子比例关系图进一步揭示了人湖河水离子主要来源于碳酸盐、蒸发岩和硅酸盐风化.

必须指出的是, 本研究仍有四个方面的工作需进一步深人. 首先, 受野外环境恶劣、地形复杂、交通不便 等因素制约, 采样点多布设在羊卓雍错及其周围的河流人湖口附近, 且仅对流域内湖水、河水和地下水样品 进行了采集，尚未开展雨水、冰雪融水和土壤样品、以及流域内各河流不同河段的水样采集工作. 其次,不同 季节的水化学特征存在差异. 本文用于水化学主离子分析的数据仅是基于 2010 年 7 月所采集的水样. 再次, 初步探讨了流域内湖水、河水以及地下水化学主离子的来源与成因,尚未进行定量分析. 最后,不同区域河 流基岩地质条件及其主要补给不同,致使不同区域内河水化学主离子来源差异显著. 在羊卓雍错流域,岩石 风化以物理风化作用为主 ${ }^{[31]}$, 流域河水化学离子来源与其所属地层分区密切相关. 随着全球气候变暖, 岩石 风化的方式和强度均会发生改变. 为此, 今后研究必须从时空尺度上加大羊卓雍错流域水样采集密度, 全面 分析流域内不同水体、人湖河流不同河段、不同季节的水化学特征,并从水循环的角度出发,基于同位素等 研究手段,进一步定量研究流域内各水体化学成分的来源、以及该地区岩石风化的速率及其对气候变化的 响应.

致谢: 感谢西藏羊湖白地水文站米玛次仁、西藏自治区气象局除多、中国林业科学研究院蒋汇川以及中国科 学院地理科学与资源研究所李炳元、孙杨、田园、李敏姣、杨依天等各位先生在野外工作各环节中所给予的 鼎立相助.

\section{5 参考文献}

[ 1 ] Gibbs RJ. Mechanism controlling world water chemistry. Science, 1970, 170(3962) : 1088-1090.

[ 2 ] Gibbs RJ. Water chemistry of the Amazon River. Geochim Cosmochim Ac, 1972, 36(9) : 1061-1066. 
-卡鲁雄曲○牙间曲 ×无名小河 $*$ 浦宗曲

- 香达曲 口卡洞加曲 $\Delta$ 嘎马林河 + 曲清河
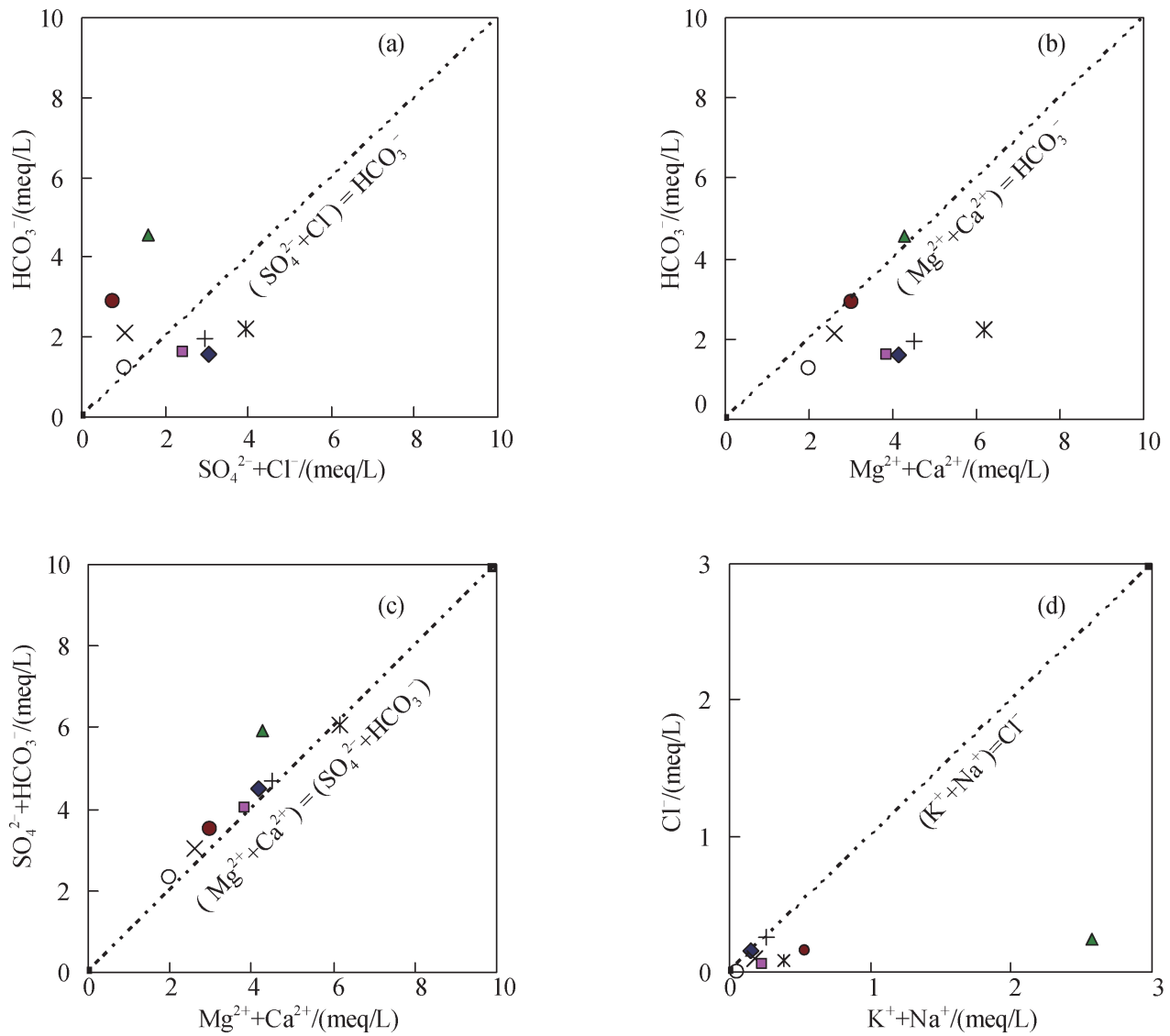

图 4 河水主要离子的比例关系

Fig. 4 Scatter diagrams between some ions of river water in the Yamzhog Yumco Basin

[ 3 ] Sarin MM, Krishnasswami S. Major ion chemistry of the Ganga-Brahamputra river systems, India. Nature, 1984, 312 : $538-541$.

[ 4 ] Vander CH, Middelburg JJ. Hydrogeochemistry of the River Rhine: Long term and seasonal variability, elemental budgets, base levels and pollution. Water Res, 1989, 23(10) : 1247-1266.

[ 5 ] Negrel P, Allegre CJ, Bernard D et al. Erosion sources determined by inversion of major and trace element ratios and strontium isotopic ratios in river water: The Congo Basin case. Earth Planet Sc Lett, 1993, 120(1/2) : 59-76.

[ 6 ] Singh AK, Hasnain SI. Major ion chemistry and weathering control in a high altitude basin: Alaknanda River, Garhwal Himalaya, India. Hydrolog Sci J, 1998, 43(6) : 825-844.

[ 7 ] Roy S, Gaillardet J, Allegre CJ. Geochemistry of dissolved and suspended loads of the Seine River, France: Anthropogenic impact, carbonate and silicate weathering. Geochim Cosmochim Ac, 1999, 63(9) : 1277-1292.

[ 8 ] Hu MH, Stallard RF, Edmond JM. Major ion chemistry of some large Chinese rivers. Nature, 1982, 298 : $550-553$.

[9] 侯昭华, 徐 海, 安芷生. 青海湖流域水化学主离子特征及控制因素初探. 地球与环境, 2009, 37(1): 11-19.

[10] 王君波, 朱立平, 鞠建廷等. 西藏纳木错东部湖水及人湖河流水化学特征初步研究. 地理科学, 2009, 29(2): 288-293.

[11] 施雅风. 山地冰川与湖泊萎缩所指示的亚洲中部气候干暖化趋势与未来展望. 地理学报, 1990, 45(1): 1-11.

［12］格桑卓玛拉巴. 近 45 年羊卓雍湖西部流域气候的变化特征初探. 西藏科技, 2007, (1): 52-53. 
[13］关志华, 陈传友, 区裕雄等. 西藏河流与湖泊. 北京: 科学出版社, 1984: 159-168.

[14］陈西平. 西藏羊卓雍湖水环境变化探索研究. 海洋与湖沼, 1990, 21(3) : 285-293.

[15] 施为光. 开发羊卓雍湖水电站对生态环境的影响. 湖泊科学, 1995, 7(2) : 178-184.

[16] 边 多, 杜 军, 胡 军等. 1975-2006 年西藏羊卓雍错流域内湖泊水位变化对气候变化的响应. 冰川冻土, $2009,31(3)$ : 404-409.

[17] Murakami T, Terai H, Yoshiyama Y et al. The second investigation of Lake Puma Yum Co located in the Southern Tibetan Plateau, China. Limnology, 2007, 8: 331-335.

[18] 鞠建廷, 朱立平, 汪 勇等. 藏南普莫雍错流域水体离子组成与空间分布及其环境意义. 湖泊科学, 2008, 20 (5) : 591-599.

[19］高 晶, 姚檀栋，田立德等. 羊卓雍错流域湖水氧稳定同位素空间分布特征. 冰川冻土, 2008, 30(2) : 338-343.

[20 ] Ye QH, Zhu LP, Zheng HX et al. Glacier and lake variations in the Yamzhog Yumco Basin in the last two decades using remote sensing and GIS technologies. J Glaciol, 2007, 53(183) : 673-676.

[21］张 菲, 刘景时, 巩同梁等. 喜马拉雅山北坡卡鲁雄曲径流与气候变化. 地理学报, 2006, 61(11): 141-148.

［22］西藏自治区地质矿产局. 西藏自治区区域地质志. 北京: 地质出版社, 1993.

[23] 朱秉启, 杨小平. 塔克拉玛干沙漠天然水体的化学特征及其成因. 科学通报, 2007, 52(13)：1561-1566.

[24] David RM. Handbook of hydrology. New York: McGraw-Hill, 1992.

[25］康世昌. 青藏高原纳木错流域现代环境过程及其变化. 北京: 气象出版社, 2011：220-264.

［26］王苏民，窦鸿身. 中国湖泊志. 北京: 科学出版社, 1998: 1-580.

[27] Berner EK, Berner RA. The global water cycle. Englewood Cliffs: Prentice-Hall, 1987.

[28 ] Chen JS, Wang FY, Xia XH et al. Major element chemistry of the Changjiang(Yangtze River). Chem Geol, 2002, 187: 231-255.

[29] Ahmad T, Khanna PP, Chakrapani GJ et al. Geochemical characteristics of water and sediment of the Indus River, TransHimalaya, India: constrains on weathering and erosion. J Asian Earth Sci, 1998, 16: 333-346.

[30] Taylor SR, McLennan SM. The continental crust: its composition and evolution. Oxford: Blackwell, 1985.

[31] Albert G, Christian FL. Weathering processes in the Ganges-Brahmaputra basin and the riverine alkalinity budget. Chem Geol, 1999, 159: 31-60. 